\title{
全国机械化耕作学术討論会
}

耕作学是农业科学中的一个重要分支。它的任 务, 是研究地力 (土壤肥力) 在耕种过程中的变化規 律，以及把地种好，为作物創造持續增产的土壤条 件。这一門年青的学科，我国是从解放后开始建立 的。为了适应农业技术改革的要求，探討士壤耕作 的农业机械化問題，中国作物学会最近在黑龙江友 䛎农場召开了一次以东北地区为主的、全国性的机 械化耕作学术討論会。会議通过論文宣讀、小組 討諭, 总結了我国十余年来机械化耕作的科学研究 成果,探討了我国耕作学領域內的一些基本問題。

耕作学在我国的建立，虽然年限很短，但由于 解放以后农业生产迅速发展的要求，在土壤耕作方 面, 已經取得了不少研究成果。无論在学术上或生 产上，都起了一定的推动作用。

深耕是增产的重要措施之一。从作物生长对耕 层的要求来說, 究竟多澡合适, 是长久以来没有得 到解决的問題, 也是实行以机械化为中心的四化 中, 需要迫切解决的問題之一。根据会上交流, 各 地在总結昱众經驗的基础上, 結合多年連續的試驗 研究，在目前的生产条件下，就水、肥、气、热的 变化，以及作物根采的分布与产量的表現等 来 看, 白田一般最樑不宜超过一尺。深耕应該結合重点施 肥, 不然深耕效果会減低, 尤其是連續深耕。

土壤經过耕种之后，在成士因素中，作物代替 了自然植被，人根据不同作物的要求，进行的耕种 活动, 也大大影响了自然因素的作用。所以不同作 物在生长过程中，对土壤影响不同; 同时不同作物 在长期的进化中，形成对士壤的具体要求不同。东 北不少国营农場，近几年来，研究提出了种过大豆 的地，耙蕉(不耕翻)种麦的耕作方法，既減少了繁 重的耕翻作业，节省了时間，爭取了季苦，也降低 了成本; 依据小麦宜于土壤比較紧实的状态特点, 利用大豆深耕的后效，比翻耕还增产。尽管大豆耙 萑种麦在应用地区、要求条件等等方面, 还需要进
一步研究，但这样一种耕作方法，开拓了利用作物 一土壤一作物相互关采的渞路。

土壤耕作一一耕、耙、耤、压等措施一一是調 养土壤, 发揮潛力的重要手段, 但要根据作物的要 求和土壤当时的物理状况，运用有度，而不是在于 越多越細越好。东北地区配合輪作、施肥、防草 等，提出了重点深耕，与浅耕、耙萑逐年交替的耕 作方法，既安排了适宜深耕細整的季节，为保証改 善耕层的土壤物理状况打下基䃨，以后几年又利用 了深耕的后效，只进行浅耕、耙花，爭取了生长季节。

东北地区生长期短，地多人少; 受过去生产条 件的限制，既不能年年施肥，及不能年 年翻 耕 細 整, 长期以来, 形成了以壠作形式的用地养地传統 种植方式。自具一套翻、扣、不的土壤耕作制度和 相应的耕具。但随着机械化的发展，由于不象平作 便于机耕机种，矛盾日趋尖銳。近年以来，結合当 地的自然条件、經济条件与生产技术习慣，进行了 大量埴作制实稹研究，探索鹃作形成的主导 因素， 以便决定在机械化条件下的发展前途。目前有些地

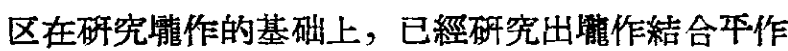
的办法，在提高产量上，起了一定的作用。

多年来，杂草一直是国营农場和人少地多地区 影响生产最楼手的一个間題。耕作学工作者，在总 結农民防除杂草經驗的基础上，研究了当地杂草的 消长規律和防除特性、不同作物抵抗杂草的 能力, 以及各种耕具的杀草性能，創造出耤一耙一粡， 㦈一耙一耕, 两耤一粡等等結合利用出苗前有利除 草时期的成套办法。

此外，会上对严格的掌握适耕时期，利用千 湿、冻融、风吹日唒自然因素的改造土壤耕性, 及 其机制和措施上，也有不少的成就。会上也还討論 了不同地区实行机珹化中可能出現的突出的問 題， 如东北地区的增作，华北地区的間套作，华南水田 的地块大小与地形不平等問題。 
关于今后的研究途径, 大家詅为应当是从生产 迫切的問題出发, 在反复总結素众經驗的基 础上, 找出綫索, 利用現代科学的方法, 进行細致的試驗 研究, 以便多快好省地取得成果。

会議經过討論研究，明确了如下的一些重大的 学术問題。

（1）机㭜化与精耕細作的关采: 精耕細作是我 国农业生产的优主传統, 发展机械化以后, 从操作 灵活自如, 耕作中可以随时根据情况調整要求的人 畜耕作, 变成标准, 作业死板的机器, 能不能实行 精耕細作, 許多人是有怀疑的。这次会議, 一方面 根据解放以来国营农場和部分社队机耕的經驗，另 一方面桴結了精耕細作的发展历史, 明确了机械化 耕作与精耕細作是应影互相促进, 而不是互相排斥 的。耕作工具的改进与动力的加强, 是逐步向精耕 細作发展的重要条件，今天所以出現了一些問題， 多牛是由于没有結合好, 或者是組織安排, 机具配 套选型、操作规程和技术水平方面的問題; 以及过 渡期間，在有些問題上，如苗眼草等，还篣要劳畜 力的配合, 逐步解决。

（2）如何看待传統的經驗：为了便于結合經驗 总結, 进行科学研究, 会上也交換了如何正确对侍 传統經驗的問題。大家䚿为传統經驗是农民在长期 生产中积榡起来的，体現了农民对于客覌规律的深 刻訩識, 但由于生产条件的限制, 这些經驗也有一 定的局限性, 因此在总結經驗, 从事科学研究解决 問題的时候, 重要的是了解传統經驗的实质, 継承 其精华, 抹加以改进提高, 对传統經驗一概加以肯 定和否定都是不正确的。

会議根据当前迅速提高农业生产的形势，也結 合着討論了 “如何結合本地区特点恢复与提高土 壤 肥力”的問題。这是耕作学科研究的中心問題。国 丙外的生产实践經驗与大量的科学研究資料, 都指 出了地力是持續坦产的基本条件。因为作物生长在 地上, 地使用不好, 培养不好, 作物就长不好。其 它各項农业技术措施的效果, 都会受到 很大的影 响。有些国家的調查統計，虽然病虫害的防除、良 种的推广、栽培方法的改进、化肥和农业机具的增
加等各项措施都大大的加强了，但結果堵产不够显 著，根本問題就是由于地力下降所致。在肥地和溲 地上，耕、种、管、收的投工投資相同，但瘦地上 的收盆相差很多。解放以来, 各地都有不少先进的 社队，产量逐年連續提高，最基本的一条，也是由 于掌握了地力的使用与培养。

地力的正确使用与培养是一个綜合性的耕作制 度問題。其中以輪作制为中心，包括相应的土壤耕 作制、施肥制以及某些地区还棈有杂草防除制、灌 溉制等。耕作制讲不是这些方面的机械相加，而是 互相渗唀、互相促进的。因此，上述娢个制度的結 合, 具有生产部署的战略意义。其中一个方面的截 然变化，其它方面也必然发生相应的变化，最終要 改变耕作制度，从而影响整个农业生产。

会上世交流了各地关于耕作制度研究的一些方 面。由于耕作学的科学研究工作, 升展的比較晚, 从事研究工作的人，也相对的少，过去几年主要集 中在調查研究上; 各部分的研究也不平衡。在輪作 制方面，多编重于作物比例、输作方式的比較 等; 关于萑口的特性, 也就是作物对士壤的影响, 研究 的很不够，然而这却是合理安排輪作的基本 依 据。 在施肥制方面, 单个作物的施肥技术, 研究得較 多, 但各单个作物的施肥技术相加, 抹不等于施肥 制，更不等于就吻合了耕作制中各部分之間的相互 要求，而有关整个施肥制的研究更不够。在土堆耕 作方面, 研究工作更为薄弱, 只深耕一項做了比較 多的工作，但这两年来，継續下来的世很少。土壤 耕作制是实現四化首先䃄到的問題。因此, 鉴于耕 作学科的研究現状, 和当前农业发展的要求, 会議 訩为应当搶先一步, 集中力量, 加强开展耕作制度 的研究, 为咱将到来的改制, 提供科学依据。定型 的国嫦农場, 目前已經提出建立符合机械化的耕作 制度的迫切要求。

为了更好的交流經驗, 統一行动, 汛速开展耕 作科学的研究工作, 尽快赶上生产的要步, 会議建 議除每年应当开一次討論会外, 耕作学的科学工作 者, 迫切需要加强联系。

\section{〔孙 渠〕}

